The Geneva Papers on Risk and Insurance, 16 (No. 59, April 1991), 143-153

\title{
Comments to the Studies on the Performance of the Insurance Industry
}

\author{
by Denis Kcssler*
}

\section{Introduction}

This special issue of The Geneva Papers on Risk and Insurance deals with a number of issues: evaluating the productivity of the insurance sector, measuring the output of an insurance company, assessing the existence of economies of scale and of scope in the insurance industry. The different questions raised and the answers given by the authors should help us to better assess the performance of insurancc companies both through time - from one period to the next - and through space - from one company to the next, from one market to the next. It is worth underlining the fact that an increasing attention is devoted to what could be called the industrial analysis of the insurance sector. It may in fact appear quite a paradox to study from an industrial perspective what is a service industry. This is of course the case, and the questions of productivity, efficiency, economies of scale or of scope, and of performances are very relevant. As it will clearly appear by reading the various papers included in those two issues, one has to adapt the analytical tools available - most often developed in the traditional industrial context - to the characteristics of the insurance service.

William Baumol gave the 1990 Geneva Lecture in Brussels in June 1990. Comments were made by Pierre Pestieau and Denis Kessler. Many question came from the floor mainly composed of insurers. Most of the other papers were presented at a seminar intitled "Productivity and Performance in Insurance", held in Paris in January 1990 under the joint auspiccs of the Geneva Association and the "Fondation pour la Rcchcrche Economique et Financière". Some papers were dircctly submittcd to the Geneva Papers on Risk and Insurance, and the questions they raised wcre so close to the main topics covcred in this special issue that they were mixed with the conference proceedings. The Geneva Association decided two years ago to launch an important intcrnational rescarch programme on "Productivity in Insurance". It sccms - by reading thesc papers gathered in thesc two special issues of the Geneva Papers on Risk and Insurance - that this programme appears to constitute a promising avenue.

\footnotetext{
* President, The French Federation of Insurance Companies, Paris.
} 


\section{Why is the productivity of the insurance industry apparently so low?}

Let us start by a presentation of William Baumol's important contribution. Professor Baumol [1] starts by stating that "the U.S. insurance industry is plagued by persistently rising costs which forces its rates to rise cumulatively to a degree that inevitably makes that industry a perpetual target of suspicion". Such trends could be considered resulting from mismanagement or greed. William Baumol consioders that this is not the case. The rise in insurance rates must be related to the nature of the technology necessary to produce the services that are the outputs of the insurance industry.

Professor Baumol reminds us that the growth rate of productivity over the post war period of the FIRE sector (Finance, Insurance and Real Estate) is very low. Moreover this rate is declining through time. The productivity growth rate of insurance agents and brokers was negative over the post war period, and was lower than the one of insurance carriers. We will come back on this specific issue delt also by Edward Wolff [14] and Andreas Hornstein and Edward Prescott [5]. During this period, insurance rates increased faster in the United States than the consumer price index.

William Baumol views "the insurance firm as a gatherer of a number of other services which it bundles into a package most useful to the party that purchases the insurance protection". This bundle encompasses administrative costs, the provision of information, the provision of legal services, the (indirect) provision of services such as medical care and repair of automobiles or other damaged properties. Unfortunatly the components of the insurance bundle have "a common characteristics: a tendency to rise in cost at a rate persistently and cumulatively greater than the economy's overall rate of inflation". William Baumol illustrates what he calls "the cost disease" by exploring the case of medical care. When taking into account the technology necessary to supply medical care, one finds that medical costs will rise faster than the costs of other products of the economy. As a matter of fact, the input prices of the medical sector grow and are not offset by any productivity increase.

William Baumol can show, by looking at the other elements of the "insurance bundle" that "the insurance industry is the supplier of a composite of services, virtually all of which are characterized by a supply technology that makes them vulnerable to the cost disease". But even at the level of the management of the insurance activities themselves, the progress in productivity is lower than expected, notably when considering the rapid computerization of the industry. William Baumol explains in his contribution why the computer revolution has had limited effects in the insurance sector.

For all those reasons, the prices of the insurance services will certainly continue to grow faster than the prices of the other products and services of the economy. The introduction of price controls - as often demanded by the public - would have very adverse effects on the supply of insurance. Therefore, an important effort of education and information is necessary to explain to the public why do insurance rates grow faster than the GNP.

Pierre Pestieau in his comments [9] discusses some of Williams Baumol's assumptions or conclusions. Pierre Pestieau raises three related questions: What is the output or rather the outputs of an insurance company. Can we measure it with the available techniques and data? Why do we need to measure the performance of the insurance industry? Pierre Pestieau gives interesting insights on those three issues, and underlines the difficulties to assess performances in the insurance industry. He is notably quite critical concerning the 
use of aggregate data drawn from the national accounts. According to Pierre Pestieau, "to correctly assess the level and the growth of both technology and efficiency, one ought to proceed at the level of insurance companies and with a larger set of data than thath based on national accounts or on the financial statements of companies".

As far as my own comments are conccrned [7], 1 insist on the fact that most of the factors mentionned by William Baumol as affecting the prices of insurance cannot be entirely considered as exogeneous to the insurance sector. It is clear that actions can be taken so as to limit the costs of the services belonging to the "insurance bundle". The costs of automobile repair may be closely watched and the insurers can collectively or individually exert some pressures to limit their growth. The same type of actions can be taken to limit medical costs. An effort of information specifically oricnted towards the judges may help limit the costs of awards resulting from lawsuits. Furthermore, prevention activities sponsored by insurers can both limit the frequency and costs of claims.

Edward Wolff's contribution [14] is devoted to the measurement of labor productivity and total productivity growth for the U.S. insurance industry over the post-war period, from 1948 to 1986. It confirms the main findings of William Baumol. Edward Wolff finds that labor productivity growth has been positive over this period. However, the total factor productivity, defined as the ratio of output to a weighted average of labor and capital inputs, has actually been negative over the same period. Edward Wolff concludes that "productivity performance has been quite poor in the insurance industry during the post-war period", and he adds that "this is true despite the rapid growth of capital intensity in the insurance industry, the high absolute and relative level of computerization and the high skill level of its work force".

These results are somehow puzzling since one should expect an industry increasing rapidly its capital stock, being computer intensive, and skill intensive to achieve high performances. Edward Wolff mentions among the factors to be taken into consideration when interpreting these results the adjustments costs linked with an extremely rapid rate of capital accumulation and computerization. The shift from a labor based industry to a capital based industry is costly. These transition costs should progressively disappear and we should expect that in the years to come the American insurance industry could benefit from productivity gains linked to previous efforts.

Rather than looking at a specific country case, Mary A. Weiss * [13] compares output, input and productivity in the non life insurance industry by studying a sample of countries composed of West Germany, Switzerland, France, Japan and the USA over the 1976-87 period. Mary Wciss insists on the fact that insurance markets are still quite close: "domestic insurers have at lcast $90 \%$ of the markct share in Sweden, Japan, Switzerland, Great Britain, West Gcrmany, Nethcrlands, ltaly and France”. Mary Weiss computes the usual divisa indexes for each country of the sample, and then adjust them to allow for multilateral comparison. She reminds us that the divisia indexes can be determined from the estimation of a translog production function if constant rcturns to scale and perfect competition arc assumed. Those arc important assumptions, and available evidencc casts some doubts on

* This paper is published in "The Geneva Papers on Risk and Insurance Theory", Vol. 16, 1991. It is commented here because it fits well in the present series of studies. 
their relevancy. However Mary Weiss considers that in the short run (considcring ycar to year changes for instance), the assumption of constant returns to scale does not introduce biascs.

When making international comparison, caution should be the rule, since many factors have to be taken into consideration to explain for instance the relative costs levels. Mary Weiss cites the marketing channels (brokers, agents, banks networks...), the tax treatment of insurance operations, the regulation (the degrce of compulsory coverage, insurance rates controls). As Mary Weiss shows, there are as far as all those matters are concerned, quite important differences between the countries under study.

Outputs are measured for a scrics of lines of busincss (motor, marinc, fire, accident, liability and other insurance). According to Mary Wciss, "output itself is unobservablc, and therefore must be proxied by an observable variable hypothetized to vary with serviccs". She adds that "scrvices arc assumed to be directly related to the amount of the losses insurers redistribute among policyholders (risk transfer scrviccs) and to the volume of funds invested for policy holders (intermediation services)". As far as the implicit prices of these risk transfer and intermediation services are concerned, Mary Weiss measures them respectively by a fraction of the loading factors (premiums - losses) and by the overall rate of return on assets. Inputs taken into account are quite standard: they consist in labor and capital costs. Intermediate inputs (paper, telecommunication...) are not taken into account.

Mary Weiss finds that "the traditional Tornquist-Theil productivity indexes vary significantly amoung countries and years... West Germany and France have the most cases of increasing productivity. The productivity index in the U.S. is punctuated by a variety of large productivity declines and increases. Japan, like the U.S., has short alternating periods of productivity declines followed by productivity increases". In fact, due to the way Mary Weiss measures outputs, these changes reflect largely the underwriting cycles. Turning to the multilateral output, input and productivity indexes, comparisons give interesting results. For instance, "the U.S. produces more output and uses more input than the other countries, however it has less than average productivity growth", West Germany is the second largest insurance producer in the sample and has measured productivity growth which is greater than average for all sample years. Switzerland has the smallest output growth but has higher productivity growth in all years... France has higher output growth than average in most years and has relatively highcr productivity growth than average in the latter part of the sample period. Finally Japan has lower output than average and the smallest relative amount of productivity growth".

\section{What is the output of the insurance sector?}

All the contributions in this special issue of the Geneva Papers are dealing with the output of the insurance sector. As soon as someone wishes to measure productivity, estimate returns to scale or appreciate competitiveness, hc is bound to choosc one or definitions of the output of the insurance sector. In William Baumol [1] and Edward Wolff's [14] contributions, the definitions chosen arc those of national accountants. Mary Weiss [13] decides to proxy the output of the insurance companies bccausc according to her it is unobservable. We will see that the other contributions devotcd specifically to the estimation of economies of scale or scope will choose to consider premiums collected or claims paid (and sometimcs 
the variable premiums - claims) as the relevant variable to assess the production of insurance companies. The financial incomes of insurance companies seem to cause problems as soon as we consider the life sector.

Two contributions are indeed directly dealing with the measurement of the output of an insurance company or of the whole insurance industry. Andreas Hornstein and Edward Prescott [5] pretend that "for many service sector industries, there currently are no reliable output measures... In the case of the insurance sector there is not even a conceptual definition of the output to guide the construction of a reasonable measure of its product".

This complex question seems to be treated differently when considering the different lines of business. C. D. O'Brien [8] focusses on the life insurance sector, Andreas Hornstein and Edward C. Prescott [5] consider the property/casualty insurance sector.

C. D. O'Brien's contribution [8] is indeed directly devoted to the question of the production of an insurance company. As he states it, "measuring output is often simpler for a manufacturing firm than for a company in the service sector, where the intangible nature of the product may cause a number of difficulties." C. D. P'Brien adds that this is particularly the case as far as life insurance is considered. This author discusses alternative measures of the life insurance firm output, namely (i) the outcome of its employing resources, and (ii) the consumer's expenditure as being used to purchase life assurance output. These issues are not merely theoretical. They have indeed numerous management implications.

In the first case, "a life assurance firm can... calculate its output as its income defined as the sum of wages and profits". It is rather easy to list all the elements to be included in the term "wages". To define "profits" represents a more delicate task: part of the surplus is redistributed to policyholders, reserves must be accumulated to back up the increase in liabilities, unrealized capital gains are the rules rather than the exception... In the second case, a company's output is merely what customers purchase from it. In that case, premiums would a priori seem to measure correctly a life company's production. This is not the case: as C. D. O'Brien reminds us, "much of the total of life assurance premiums which a company receives will effectively be transfer payments within the body of policy holders". Isolating what part of the premiums which a company receives is not a transfer payment is not an easy task. One will certainly include some of the company's expenses (wages, purchases of intermediate goods and services...). Questions arise when considering commissions paid to the agents, indirect taxes such as stamp duty, shareholders profit... In any case, the true intertemporal nature of an insurance contract complicates the appealing distinction between the "transfer" and "service" parts of a policy.

C. D. O'Brien is then led to propose an innovative approach emphasizing output as being the servicing activities involved: "these services may be handling in the sense of selling + administration + investment, or they may be insurance in terms of shareholders's capital enabling valuable guarantees to be given". By considering "units of output" and identifying "prices" for each of the functions carried, it is possible, according to C.D. O'Brien, to better measure the production of an insurance company, assess its productivity and check the existence of economies of scale or scope. C. D. O'Brien illustrates with a few numerical exemples the method he proposes.

Andreas Hornstein and Edward Prescott [5] consider that "in the case of insurance sector, measuring inputs is not without problems but these problems are not different from those for other sectors". The true difficulties lie in the measurement of the outputs. Unless 
a clear definition of what produces the insurance industry is found and clearly given, any measure of its productivity may appear questionnable. Andreas Hornstein and Edward Prescott show that in the U.S. according to the standard approach of productivity analysis, "the service and FIRE industries not only show below average productivity growth, but productivity is actually declining for FIRE and stagnating for services". These conclusions are similar to the ones reached by William Baumol [1] and Edward Wolff [14]. But Andreas Hornstein and Edward Prescott consider that the output of the insurance sector is not correctly measured in the national accounts: "the nominal output produced by the non life insurance sector is currently measured by the net premiums earned in the sector, that is gross premiums earned minus benefits paid". But they ask "what is the constant dollar value of the commodity or commodities produced?". They criticize the method currently used by national accountants to estimate the real output for the insurance sector, which consists in extrapolating the base period net premiums using deflated gross premiums (deflated by a consumer price index). Andreas Hornstein and Edward Prescott give two examples to show that the current measurement of real output in property/casualty insurance is misleading: "with the current procedure, greater administrative productivity that results in lower contract prices will reduce gross premiums and therefore measured constant prices output of the insurance sector". The conclusion is harsh: "the only possible conclusion is that the current measure of real product of the casualty insurance sector is worthless for estimating productivity change in that sector".

Andreas Hornstein and Edward Prescott propose a new approach. They argue that, when searching to define the real output, one should start by considering that the relevant commodity is an insurance contract and the gross premium is its price. The authors develop a general equilibrium model where components of the commodity vector are insurance contracts of a particular type: "insurance contracts are outputs of the business sector and inputs to the household sector". Insurance contracts are differentiated commodities to be defined carefully. Andreas Hornstein and Edward Prescott take the example of the automobile insurance market where the premiums depends upon a number of factors including the amount of coverage, the deductibility level, the nature of the use of the car and the car model to be insured. The pricing function of a given contract depends upon the claim distribution. It can be estimated by using the average values of claims and the number of claims. This function can then be used to estimate the output and its real change over time. This innovative method has not ben yet empirically implemented. This ought to be soon the case, to see if the usual conclusions about the low productivity of the insurance sector are still valid when measuring more strictly the output of the insurance sector.

\section{Are there economies of scale and of scope in the insurance industry?}

The existence of economies of scale in the insurance industry is a very debated issue. There has been a large number of studies trying to assess cconomies of scale for life and non-life insurance companies. Jean Marc Suret [11] provides us with a survey of the main studies of the costs functions of companies in the property/casualty insurance industry. Most of them delt with the U.S. case. We have now evidence concerning the United Kingdom, France, Italy and Canada. Establishing whether or not there are economies of scale has important practical implications. As Roland Eisen [3] and Luigi Prosperetti [10] remind us, the issue of the existence of economies of scale is very relevant in Europe at a time when most barriers preventing competition are crumbling, thus enlarging the market. Will there be strong pressures favouring the concentration of the insurance sector? 
Let us remark, before presenting these studies, that all of them, even when they mention the difficulties to measure the true output of an insurance company or of the insurance industry as a whole, use the available data, in most cases the premiums collected and in some cases, the claims paid. In other words, many of the fundamental remarks made by C. D. O'Brien [8] or by Andreas Hornstein and Edward Prescott [5] are de facto overlooked.

Roland Eisen [3] gives an interesting presentation of the construction of the EC insurance market: "the way to the internal market is increasing liberalization of the highly regulated and segregated market and releasing competitive forces". This should result in a general dccrease of the averagc insurance prices lcvel - in other words, the prcmiums charged for a given risk. The decrease in prices will be the sign that the average efficiency of the insurance industry has incrcased. The insurance market is cnlarging: will this well known phenomenon affect the sizc of insurance companies? Roland Eiscn's aim is precisely to study the relationship between market sizc and firm size, and to estimate the minimum efficient size (MES) of a company. Roland Eisen discusses different concepts of MES - (i) the average firm size, (ii) the output of that individual plant which is located at the 50 percent point of the cumulative size distribution, (iii) the average plant size amongst the largest plants accounting for $50 \%$ of industry output and (iv) the number of firms of the same size which could exist on the market without changing the degree of concentration. The author then estimates the values of the different MES variables, evaluates the relationship between the MES values and the market size in 11 countries, and tests the correlation between the number of insurance firms and market size in different countries. The results obtained by Roland Eisen are that "insurance firms are larger on larger markets", "insurance markets show higher concentration than is necessary from an efficiency standpoint", and "the insurance industry is characterized by constant returns to scale over a wide range of output". Therefore, one should expect from the completion of the internal market a rise in the average size of insurance companies.

According to Luigi Prosperetti [10], the Italian non life insurance market has been both "strongly sheltered from competition and until recently weakly regulated". Let us remark that this opinion is shared by Antonio Borghesi [2]. The transition to the Great Market may cause some problems: first, the average "costs/premiums" ratio in the non life sector is significantly higher in Italy than in the rest of Europe, and second, there are a large number of small firms. The question of course is to know if the apparently lower average performances fo the italian insurance industry may be attributed to the high number of very small insurance companies. Luigi Prosperetti follows the classical and rather simple cost/size relationship approach where the output is measured by direct premium income and the inputs are the different distribution and operating costs. The sample is composed of 151 non life insurance companies observed in 1988. The author splits his sample into three sub categories. Luigi Prosperetti concludes that there are scale economies and "as market conditions in Italy becomes more competitive, one should cxpect a rather drastic restructuring of the insurance company to take place, which will entail a gradual elimination of the very small companies and widespread cost reduction in the remaining firms". It would be interesting to see whether these results are sensitive to the disagregation of the sample into sub categories as it is in the UK casc.

Antonio Borghesi [2] introduces a series of interesting distinctions between concepts frequently found in the literature devoted broadly to the performances of a firm or of an industry: effectiveness, efficiency, productivity, economicy and profitability. For instance, 
the distinction between productivity and "economicy" according to Antonio Borhesi is the following: productivity is the rationalization of operations leading to a maximization of physical results achieved with respect to the means employed - and "economicity" stands for the ways to minimize the monetary costs necessary for producing a given result. For each of the above mentionned concepts, Antonio Borghesi indicates how we can measure them in the insurance industry. The numerical calculation of the various ratios proposed is made difficult in the Italian case by the cruel lack of data, and Antonio Borghesi limits himself to compute some indices of the "economicity" and profitability of the Italian insurance firms. The results he presents are characterized by an apparently very wide dispersion of the relative performances of Italian insurance firms, a conclusion quite close to the one reached by Fecher, Perelman and Pestieau [4] studying the French market with a totally different method. How can survive on the same market companies with so different performances? It seems that the standard conclusion of industrial economics saying that market forces lead to a rather similar degree of performances is not verified in the insurance industry.

In exploring the U.K. life insurance case, Geraldine Kaye [6] discusses the choice of the variable to be considered as the output of the life insurance industry. After an interesting analysis of the various possible definitions, Geraldine Kaye finally chooses the premiums, and states that by doing so she adopts the management perspective rather than the consumer's. She tests a single equation model using data from repeated surveys of a single cross section sample in different periods of time. The single equation approach where log of expenses are related to the log of premiums is considered by Geraldine Kaye as avoiding the multicollincarity problems very often encountered in models designed to estimate economy of scale. By splitting the sample into different sub-categories characterized by the amount of premiums collected, Geralding Kaye finds significant differences, and "this would indicate that economies of scale could exist and that if so their extent increases with the size of the company. Unfortunatly, the results appear very sensitive to the choice of subcategories. According to the choice of disagregation of data - what the author calls in her contribution the choice of "break points" - economies of scale appear or not. Furthermore, there seems to be no a priori grounds for disaggregating data. Geralding Kaye concludes her study by saying that "economies of scale exist for the life indstry and that the rate of proportionate increase of expenses against the proportionate increase of premiums is about $92 \%$ which has been constant during the period 1980-86".

Fabienne Fecher, Sergio Perelman and Pierre Pestieau [4] find economies of scale in France by using a translog cost function estimated on a panel data covering 84 life and 243 non life companies over the period 1984-89. They use two output variables: gross premiums or claims. In both cases, for life and non life companies, economies of scale do appear, whatever the different institutional forms (stock, foreign, mutual and public companies). Fabienne Fecher, Sergio Perelman and Pierre Pestieau using the same panel data analyze also the productivity efficiency of non life and life insurance on the basis of a stochastic production frontier. In this case, the authors retain premiums as output variable. The idea is to determine for a given vector of input the maximum output possible (or reciprocally for a given vector of output, the minimum set of inputs). This frontier of maximum production when the inputs vary is estimated from actual balance sheet data. Repeated over time, the method may help to see whether there is or not an increase in overall productivity that would result in a displacement of the efficiency frontier. 
The results of Fabienne Fecher, Sergio Perelman and Pierre Pestieau are simply phrased: "overall the average level of efficiency is very low and the dispersion very high". They try to see how the relative degree of efficiency vary with the institutional type, the reinsurance ratio, the scale proxied by gross premiums, the claims to premiums ratio and the commission ratio of companies. To explain their findings, they evoke the high degree of segmentation of the French insurance market. If such a segmentation did no exist, a large number of firms would be driven out of the market. The efficiency frontier approach followed by Fabienne Fecher, Sergio Perelman and Pierre Pestieau is very encouraging and innovative even though the available data are not optimal to follow.

Robert Teyssier [12] uses also the translog production function to estimate scale economies in the French Insurance Industry. He underlines the fact that the insurance industry is not homogeneous. Robert Teyssier reminds us that to refer to a representative cost function implies the implicit assumptions of homogeneous technologies, of homogeneous behaviours of producers, and of homogeneous sets of input and output prices. He insists therefore on the fact that in the real world many distinctions should be made, according for instance to the nature of the insurance firms (mutual, public, bank subsidiaries...), to the nature of the risks carried (life insurance on one side and property/casualty insurance on the other), to the distribution networks used (brokers, tied agents, salaried workers...), and so on. $\mathrm{He}$ also criticizes the fact that in most cases the financial activity of insurance companies are not taken into account when estimating economies of scale or of scope. This is misleading since, first, certain costs are directly linked to the financial activity of insurance firms, and, second, the constitution of provisions in the life insurance sector should appear as a cost.

There are indeed many different types of costs, some of them being substitutable, other being complementary, and one should pay attention to see how each of these may lead to economies of scale and scope. With data relative to French insurance companies, Robert Teyssier finds significant scope economies in both the life and non life sectors.

But Robert Teyssier also pinpoints a specific phenomenon often overlooked: the larger the company the lower the need for equity per unit of premium. The proof of this statement is rather straightforward "the less the law of large numbers applies to contracts for a given insurance company, the more it is necessary to set aside reserves for each contract of insurance, in order to constantly minimise the probability for bankruptcy". Empirical tests seem to confirm this assumption.

Jean-Marc Suret [11] investigates scale and scope economies in the Canadian property/ casualty insurance. After a brief survey of the previous studies dealing with economies of scale, Jean-Marc Suret's aim is to solve the main five following problems unsolved in previous studies: "(i) the utilization of a single product framework, (ii) the measurement of output in the insurance industry, (iii) the assumption of restrictive functional forms to represent the production technology, (iv) the failure to assess the robustness of various measures of the presence of scale and scope economies and (v) the failure to compute standard errors of the estimates of the parameters that caracterise the cost function". JeanMarc Suret's contribution tries to overcome those different failures.

The use of the translog cost function allows the estimation of a U-shaped cost curve and of cost elasticities that vary with the size of the insurance company. The translog function is flexible enough to avoid imposing on a priori grounds a too rigid production function 
to the insurance firm. Four lines of business are considered: property, automobile, civil liability and other types of insurance. Outputs are measured by claims and by net premiums (premiums - claims). The factors of production are labour, rentals and capital, but the cost of the latter is taken as constant. The model is estimated on a sample of 180 companies over the period 1986 to 1988.

The empirical results of Jean-Marc Suret are quite different from Robert Teyssier's conclusions. According to Jean-Marc Suret, there are significant economies of scale only for medium sized companies. But there are neither significant cost complementarities between insurance products (for instance between the two main product lines of property/ casualty and automobile), nor clearcut economies of scope (there seems even to be diseconomies of scope!) These results could explain why there are many small and undiversified insurance companies in Canada. To understand the differences between the Canadian and the French results requires certainly some further study of their respective regulation, taxation, labour organization, and so on.

This introduction aims at inciting to read all these contributions. They are very rich both in ideas and data. They propose interesting methodologies that should be applied whenever possible. They open new areas of research and at the same time prevent us to take for granted numerous statements quite often made on and in the insurance industry. They will help the managers when considering alternate strategies: to grow or not, to diversify or not, to invest abroad or not...

Among the questions to be explored further, let me just mention some of the most promising ones. Why do performances appear to vary so much when considering respectively life or non life insurance companies? How can we improve the understanding of the insurance firms offering a large vector of outputs - the famous multiproduct insurance company? Can we theoretically better assess the form of the production function of insurance companies? How can we correctly integrate the financial activities of insurancce companies in their function? How can we explain the apparently high dispersion of performances of insurance companies operating in a given market? How can we better assess the role of insurance in a general equilibrium framework? How can we draw comparable measures of efficiency, productivity, and so on, both at the firm and at the industrial levels? 


\section{REFERENCES}

[1] BAUMOL, William, (1991), "Technological Imperatives, Productivity and Insurance Costs", The Geneva Papers on Risk and Insurance Issues and Practice, No. 59.

[2] BORGHESI, Antonio, (1991), "Some Considerations on Productivity and Performance in Insurance: Preliminary Findings of a Study of the Italian Insurance Industry, The Geneva Papers, No. 60 .

[3] EISEN, Roland, (1991), "Market Size and Concentration: Insurance and the European Internal Market 1992", The Geneva Papers, No. 60.

[4] FECHER, Fabienne, PERElMAN, Sergio and PESTIEAU, Pierre, (1991), "Scale Economies and Performance in the French Insurance Industry", The Geneva Papers, No. 60.

[5] HORNSTEIN, Andreas and PRESCOTT, Edward C., (1991), "Measures of the Insurance Sector Output", The Geneva Papers, No. 59.

[6] KAYE, Geralding, (1991), "Economies of Scale in UK Life Insurance Companies: an Empirical Approach", The Geneva Papers, No. 60.

[7] KESSLER, Denis, (1991), "Technological Imperatives, Productivity and Insurance Costs: a Comment", The Geneva Papers, No. 59.

[8] O'BRIEN, C.D., (1991), "Measuring the Output of Life Assurance Companies", The Geneva Papers, No. 59.

[9] PESTIEAU, Pierre, (1991), "Technological Imperatives, Productivity and Insurance Costs: a Comment", The Geneva Papers, No. 59.

[10] PROSPERETTI, Luigi, (1991), "Economies of Scale in Italian Non Life Insurance", The Geneva Papers, No. 60.

[11] SURET, Jean-Marc, (1991), "Scale and Scope Economies in the Canadian Property and Casualty Insurance Industry", The Geneva Papers, No. 59.

[12] TEYSSIER, Robert, (1991), "Economies of Scale and Economies of Diversification in Insurance Business: Some Elements of valuation", The Geneva Papers, No. 60.

[13] WEISS, Mary A., (1991), "International P/I Insurance Output, Input and Productivity Comparisons", The Geneva Papers on Risk and Insurance Theory, Vol. 16, 1991.

[14] WOLFF, Edward N., (1991), "Productivity Growth, Capital Intensity and Skill Levels in the U.S. Insurance Industry, 1958-1986", The Geneva Papers, No. 59. 